Check for updates

Cite this: RSC Adv., 2019, 9, 24314

Received 6th April 2019

Accepted 24th July 2019

DOI: 10.1039/c9ra02590a

rsc.li/rsc-advances

\section{Two step, one-pot sequential synthesis of functionalized hybrid polyheterocyclic scaffolds via a solid state melt reaction (SSMR) $\dagger$}

\author{
Manickam Bakthadoss, (D) *a Jayakumar Srinivasan, ${ }^{a}$ Mir Ashiq Hussain ${ }^{a}$ \\ and Duddu S. Sharada (D) *b
}

\begin{abstract}
A new one pot assembly of highly functionalized benzo[a]phenazinone fused chromene/bicyclic scaffolds via a domino Knoevenagel intramolecular hetero-Diels-Alder (IMHDA) strategy using a solid state melt reaction (SSMR) of 2-hydroxynaphthalene 1,4-dione, O-phenylenediamine, $O$-allyl salicylaldehyde/Ovinyl salicylaldehyde derivatives is reported. The formation of five new bonds (two $\mathrm{C}-\mathrm{C}$ bonds and three $\mathrm{C}-\mathrm{O}$ bonds), three six-membered rings, and three stereogenic centers in a one-pot manner is very attractive. Ease of reaction with short time, good yields with water as the only byproduct and work up free procedure are some of the excellent features of the present protocol.
\end{abstract}

Multicomponent reactions (MCRs) ${ }^{1}$ are known to construct complex structures from simple starting materials in a rapid and highly efficient manner where the production of wastes is minimized. Those multicomponent reactions which are carried out in a 'one-pot' MC sequential manner provide a high degree of reaction mass efficiency, which is crucial in the development of modern synthetic methodology for drug discovery and pharmaceutical programs. ${ }^{2}$ Enormous work has been carried out in the field of multicomponent reactions in the past decade where several MCRs have been developed and extensively used in natural product synthesis and drug discovery. The Ugi reaction is a prime example of a four-component reaction that has been found to be a powerful and efficient method for the preparation of $\alpha$-amino amides both in academia and industry. ${ }^{3}$ Therefore, the development of new MCRs for the synthesis of biologically active molecules continues to attract considerable attention for their atom- and step economy features.

Heterocycles having nitrogen atom are widely available in nature and possess diverse and important biological activities. ${ }^{4}$ Phenazines are a group of organic compounds known to the mankind since past 150 years and are known to exhibit significant biological activities such as antimalarial, fungicidal, trypanocidal, antiplatelet, etc. ${ }^{5}$ A large number of drug molecules bearing the phenazine scaffold have been designed and evaluated in the recent years. The phenazines motif possess two

${ }^{a}$ Department of Chemistry, Pondicherry University, Pondicherry-605 014, India. E-mail: bhakthadoss@yahoo.com

${ }^{b}$ Department of Chemistry, Indian Institute of Technology Hyderabad, Kandi, 502285, Sangareddy, Telangana, India

$\dagger$ Electronic supplementary information (ESI) available. CCDC [1906333 and 1906667]. For ESI and crystallographic data in CIF or other electronic format see DOI: 10.1039/c9ra02590a dentate $\mathrm{N}$ atoms with three fused aromatic rings and an electron deficient conjugated system. The presence of the above features in phenazines give them an ability to form hydrogen bonds, ionic bonds, and $\pi-\pi$ interactions with relative ease, and their use has also been demonstrated in supramolecular chemistry for molecular recognition (MR), supramolecular selfassembly (MS-A), and organic optic electronics materials. ${ }^{6}$ Few representative examples of phenazine and its derivatives are shown in the Fig. 1.

Chromenes and their derivatives are privileged scaffolds due to their ubiquitous presence in many natural products and synthetic molecules. ${ }^{7}$ Chromenes are also an important class of compounds displaying interesting biological activities against prostate cancer (DU-145) and breast cancer (MCF-7). ${ }^{8}$ Additionally, they have medicinal qualities such as antiviral and antimicrobial activity. ${ }^{9}$ Chromenes have also found their use in medicine, health-promoting agents, and photochromic materials. ${ }^{10}$

In recent years, the domino-Knoevenagel-hetero-Diels-Alder reaction (DKHDA) which was extensively studied by Tietze's group constitutes an important process for the preparation of complex compounds having interesting biological properties. ${ }^{\mathbf{1 1}}$ The Diels-Alder reaction is important since it allows the
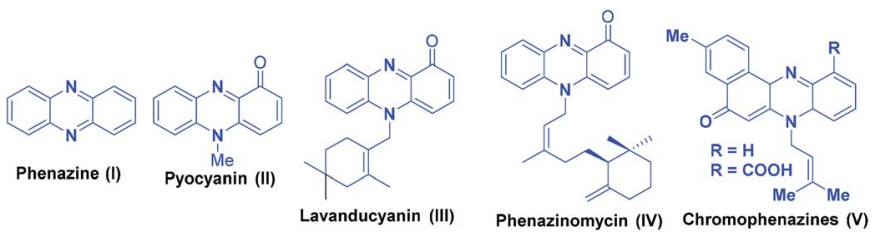

Fig. 1 Some of naturally occurring phenazine derivatives. 
formation of functionalized rings where there is complete control on regio-, diastereo-, and enantioselectivity. Moreover, the concerted nature of the Diels-Alder reactions allow the selective formation of up to three stereogenic centers in a single reaction step. Majority of the reactions reported on DKHDA have utilized 1,3-dicarbonyl compounds such as dimethyl barbituric acid, Meldrum's acid and 1,3-indanedione. ${ }^{12}$ Additionally, other active methylene compounds like 1-phenyl-3-methyl pyrazolone, 4-hydroxy-coumarin, dihydroindole-2-thione, benzoylacetonitrile, 4-hydroxydithiocoumarin have been also used; ${ }^{13}$ but phenazinones have never been employed in DKHDA reactions. To the best of our knowledge, there are no reports on intramolecular DKHDA reactions using phenazinone as the coupling partner. Due to our interest in the construction of bioactive fused chromenophenazinone derivatives and since this molecule contains a 1,3-dicarbonyl as well as a 1,3-imine moiety, it would be very challenging to control the regioselectivity of the molecule; therefore phenazinone scaffold can act as a model substrate for an intramolecular DKHDA. We envisaged that a series of angular polycyclic chromeno fused phenazinone derivatives could be obtained and it is possible that the final hybrid compounds will result in being more selective and efficient than chromene and phenazinone compounds in biological assays.

In this direction, we have decided to develop a new method for the preparation of novel benzo[a]phenazinone fused chromene/bicyclic scaffolds via a domino Knoevenagel intramolecular hetero-Diels-Alder (IMHDA) strategy using a solid state melt reaction (SSMR). As part of our research program for the development of new synthetic methods in heterocyclic chemistry ${ }^{14}$ and solid state melt reactions, ${ }^{15,16}$ we would like to report a simple and a general domino three-component reaction of 2-hydroxynaphthalene-1,4-dione, $o$-phenylenediamine and $O$-allylated/vinylated salicylaldehyde for the synthesis of pentacyclic benzo[a]phenazinone fused chromene/bicyclic scaffolds under environmentally benign reaction conditions (Scheme 1).

We have started this study by melting 2-hydroxynaphthalene1,4-dione (2), o-phenylenediamine (1), and (E)-methyl 2-((2formylphenoxy)methyl)-3-phenylacrylate (3) at $180{ }^{\circ} \mathrm{C}$ for $1 \mathrm{~h}$ in solvent free condition. Unfortunately, we could not obtain any desired product and the formation of a complex mixture was observed. To minimize the formation of the side products, the 2-hydroxynaphthalene-1,4-dione (2) and $o$-phenylenediamine

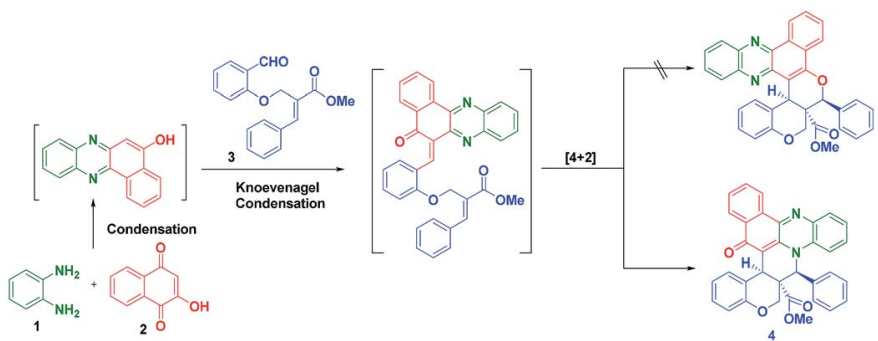

Scheme 1 Synthetic approach to benzo[a]phenazinone fused chromenes.
(1) were first melted at $180{ }^{\circ} \mathrm{C}$ for 10 minutes to form the intermediate benzo[a]phenazin-5-ol. Subsequently, $(E)$-methyl 2-((2-formylphenoxy)methyl)-3-phenylacrylate 3a was added and the mixture was melted under the same temperature for $1 \mathrm{~h}$ which afforded the desired hybrid product chromene fused benzo $[a]$ phenazinone $\mathbf{4 a}$ (ester moiety in ring junction) in $78 \%$ yield as shown in Table 1.

This two-step procedure allows the one-pot three-component reaction to be controlled, avoiding the separation of intermediates, as well as time-consuming and costly purification processes. It is also important to mention here that the reaction is not only diastereoselective, but also chemoselective. Among the two possible hetero diene such as $\mathrm{C}=\mathrm{O}$ and $\mathrm{C}=\mathrm{N}$ from phenazine ring, only the $\mathrm{C}=\mathrm{N}$ diene is involved in the reaction which clearly shows the chemo-selective nature of the reaction (Fig. 2).

To expand the scope of this one pot reaction, by following the aforementioned procedure, we treated a variety of $O$-allylated

Table 1 Synthesis of heptacyclic chromene fused benzo[a] phenazinones ${ }^{a, b, c}$
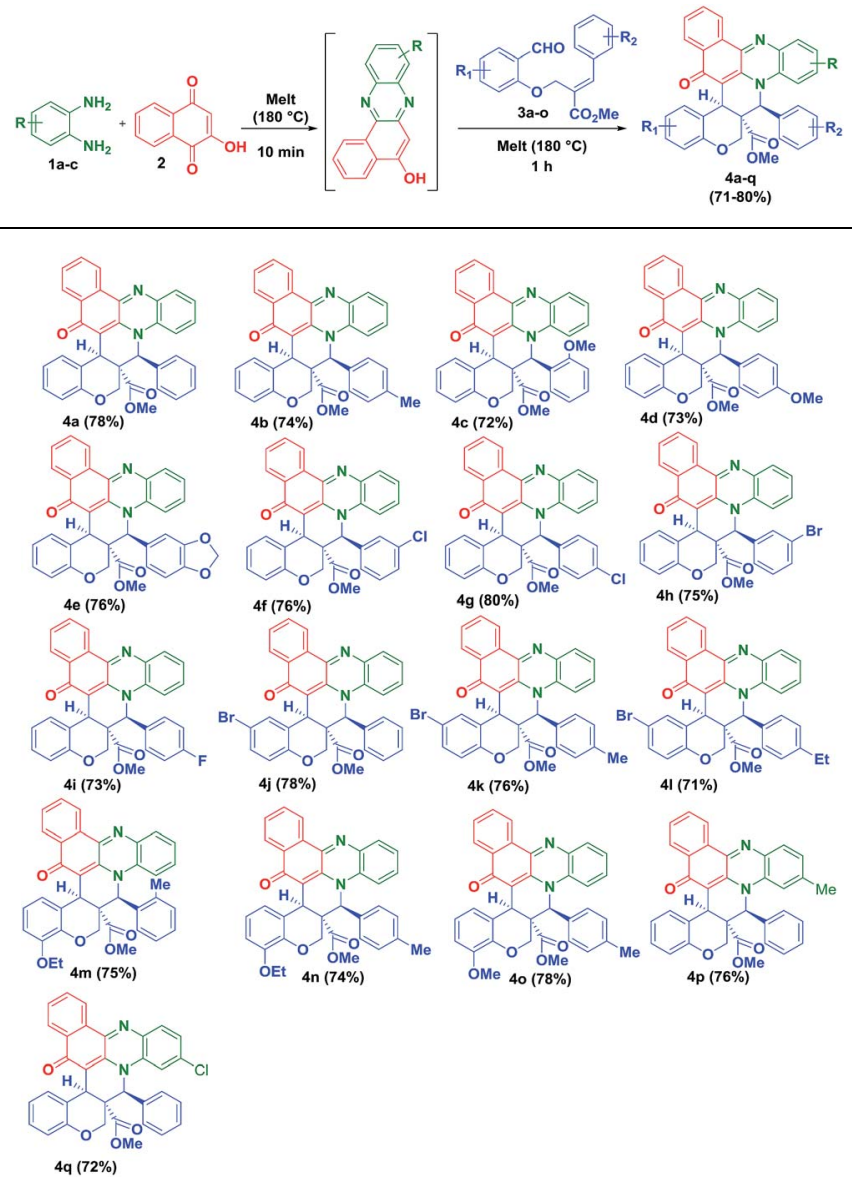

${ }^{a}$ All reactions were carried out on $1 \mathrm{mmol}$ scale of $o$-phenylenediamine (1a-c) 2-hydroxynaphthalene-1,4-dione (2), and $O$-allylated salicylaldehyde derivatives (3a-o) at $180{ }^{\circ} \mathrm{C}$ for $1 \mathrm{~h} .{ }^{b}$ Isolated yield of the pure products $(\mathbf{4 a - q}) \cdot{ }^{c}$ All compounds were fully characterized (see ESI). 

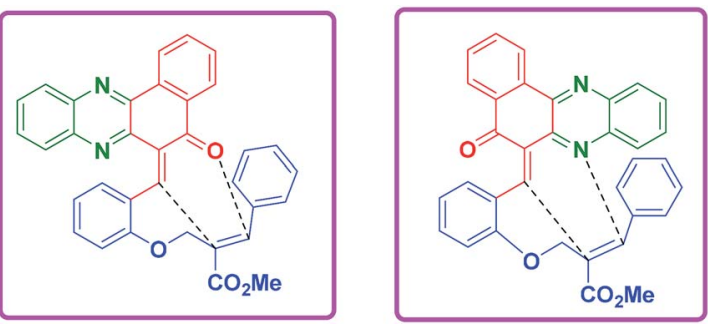

Fig. 2 Competitive two different heterodienes present in the intermediate.

Table 2 Synthesis of heptacyclic chromene fused benzo[a] phenazinones ${ }^{a, b, c}$
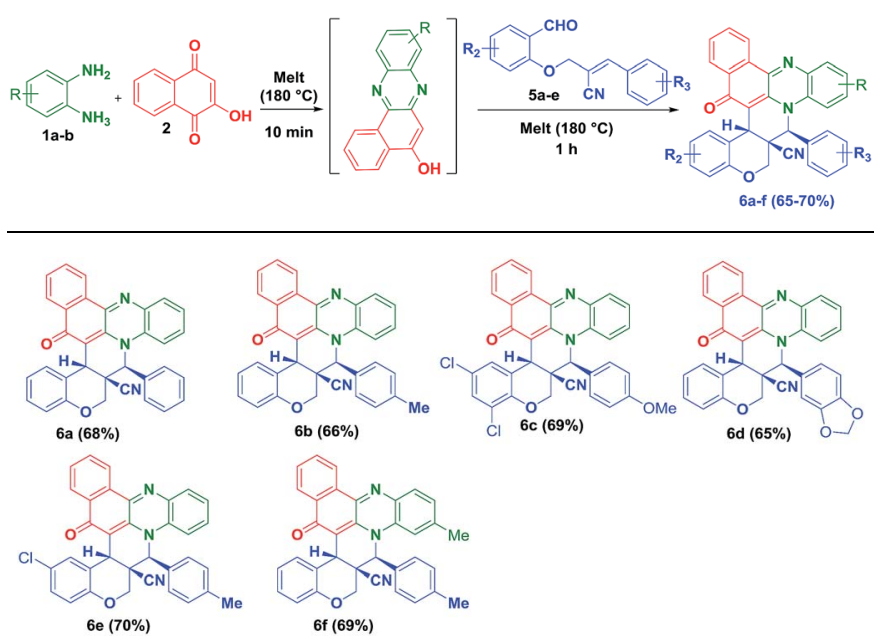

${ }^{a}$ All reactions were carried out on $1 \mathrm{mmol}$ scale of $o$-phenylenediamine (1a-b), 2-hydroxynaphthalene-1,4-dione (2), and $O$-allylated salicylaldehyde derivatives $(\mathbf{5 a}-\mathbf{e})$ at $180{ }^{\circ} \mathrm{C}$ for $1 \mathrm{~h} .{ }^{b}$ Isolated yield of the pure products $(\mathbf{6 a - f}) .{ }^{c}$ All compounds were fully characterized (see ESI)

Table 3 Synthesis of benzo[a]phenazinones fused bicyclic scaffolds ${ }^{a, b, c}$
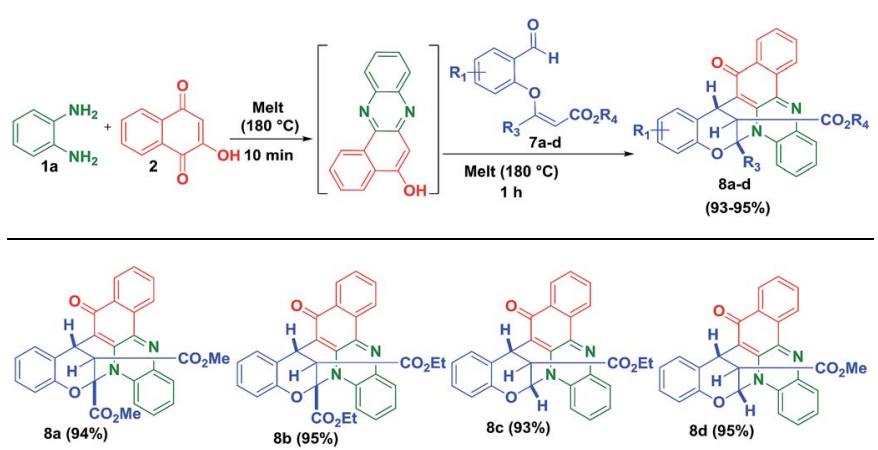

${ }^{a}$ All reactions were carried out on $1 \mathrm{mmol}$ scale of $o$-phenylenediamine (1a), 2-hydroxynaphthalene-1,4-dione (2), and vinylogous carbonate derivatives (7a-d) at $180{ }^{\circ} \mathrm{C}$ for $1 \mathrm{~h}$. ${ }^{b}$ Isolated yield of the pure products $(\mathbf{8 a}-\mathbf{d}) \cdot{ }^{c}$ All compounds were fully characterized (see ESI).
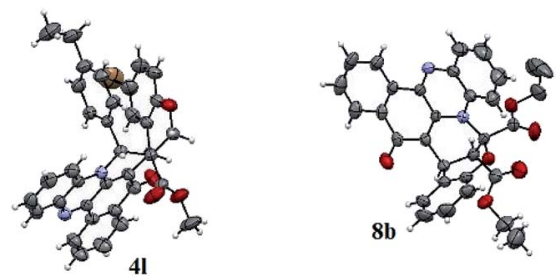

Fig. 3 X-ray crystal structure of $4 \mathrm{l}$ and $8 \mathrm{~b} .{ }^{17}$

salicylaldehyde derivatives (3b-o) and melted with $o$-phenylenediamine (1a-c), 2-hydroxynaphthalene-1,4-dione (2), which successfully yielded the desired fused novel benzo[a]phenazinone fused chromene derivatives $\mathbf{4 b}-\mathbf{q}$ in $71-80 \%$ yields. The isolated yields of the pure products $(\mathbf{4 b}-\mathbf{q})$ are summarized in Table 1. The reaction is highly diastereoselective and chemoselective in nature, which has been, clearly evidenced in the ${ }^{1} \mathrm{H}$ NMR spectroscopy.

To check the generality of the reaction, we melted the $O$ allylated salicyldehyde derivatives (5a-e) bearing nitrile functionality, with $o$-phenylenediamine $(\mathbf{1} \mathbf{a}-\mathbf{b})$ and 2hydroxynaphthalene-1,4-dione (2) for $1 \mathrm{~h}$ at $180{ }^{\circ} \mathrm{C}$ which successfully provided the anticipated hybrid benzo $[a]$ phenazinone fused chromene derivatives (6a-f) (angularly substituted nitrile moiety) in $65-70 \%$ yield (Table 2 ).

Further, to explore this methodology, we have prepared a variety of vinylogous carbonate derivatives $(\mathbf{7 a}-\mathbf{d})$ and treated with o-phenylenediamine (1) and 2-hydroxynaphthalene-1,4dione (2) for $1 \mathrm{~h}$ at $180{ }^{\circ} \mathrm{C}$ which successfully provided the novel benzo[ $[a]$ phenazinones fused bicyclic scaffolds

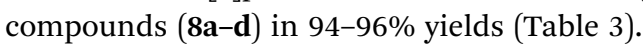

This one pot domino reaction is highly stereoselective in nature and was evidenced by single crystal X-ray analyses. ${ }^{17}$ The stereochemistry of the compounds $\mathbf{4 l}$ and $\mathbf{8 b}$ is confirmed by $\mathrm{X}$ ray crystallographic analysis (Fig. 3). It can be seen from the crystal structure that the phenyl group and the adjacent ester moiety are in the anti-orientation in benzo[ $a]$ phenazinonefused chromene (41) which is due to the initial trans geometry of the phenyl group and ester moiety present in the double bond at vicinal position of the compound 4l. Similarly, the ORTEP diagram of compound $\mathbf{8 b}$ (Fig. 3) clearly demonstrates that the relative stereochemistry of the ester at the ring junction and the ring junction hydrogen are in syn-orientation with each other.

\section{Conclusions}

In conclusion, we have successfully developed a novel and efficient method for the synthesis of heptacyclic frameworks containing a benzo $[a]$ phenazinone fused chromene/bicyclic scaffolds via one pot multicomponent domino Knoevenagel intramolecular hetero Diels-Alder (IMHDA) strategy using a Solid State Melt Reaction (SSMR) in a highly diastereoselective and chemoselective fashion. This one pot two-step reaction leads to a novel class of heterocyclic skeleton, which creates five new bonds, three new rings, three contiguous stereogenic 
centres and one of them being an all carbon quaternary centre. Various advantages of this procedure include solvent and catalyst free synthesis, high yields and short reaction time. Additionally, the only by-product in this reaction is water, which makes this protocol very attractive in green chemistry point of view.

\section{Conflicts of interest}

There are no conflicts to declare.

\section{Acknowledgements}

We thank CSIR (New Delhi) [02(0303)/17/EMR-II] for the financial support. J. S. thanks CSIR, New Delhi for his SRF fellowship.

\section{Notes and references}

1 For some reviews on MC reactions, see: (a) R. M. Armstrong, A. P. Combs, P. A. Brown and T. A. Keating, Acc. Chem. Res., 1996, 29, 123-131; (b) A. Dömling and I. Ugi, Angew. Chem., Int. Ed., 2000, 39, 3169-3210; (c) H. Bienaymé, C. Hulme, G. Oddon and P. Schmitt, Chem. -Eur. J., 2000, 6, 33213329; (d) A. Dömling, Curr. Opin. Chem. Biol., 2000, 4, 318323; (e) A. Dömling, Chem. Rev., 2006, 106, 17-89; $(f)$ N. Isambert and R. Lavilla, Chem. -Eur. J., 2008, 14, 84448454; (g) B. Ganem, Acc. Chem. Res., 2009, 42, 463-472; (h) E. Ruijter, R. Scheffelaar and R. V. Orru, Angew. Chem., Int. Ed., 2011, 50, 6234-6246.

2 J. Andraos, Org. Process Res. Dev., 2005, 9, 149-163.

3 (a) A. Doemling and I. Ugi, Angew. Chem., Int. Ed. Engl., 2000, 39, 3169-3210; (b) H. Bienaymé, C. Hulme, G. Oddon and P. Schmitt, Chem.-Eur. J., 2000, 6, 3321-3329.

4 Dictionary of Alkaloids, ed., I. W.Southon and J.Buckingham, Chapman \& Hall, New York, 1989.

5 (a) J. B. Laursen and J. Nielsen, Chem. Rev., 2004, 104, 16631686; (b) M. Makgatho, R. Anderson, J. O'Sullivan, T. Egan, J. Freese, N. Cornelius and C. Van Rensburg, Drug Dev. Res., 2000, 50, 195-202; (c) V. Andrade-Nieto, M. Goulart, J. F. da Silva, M. J. da Silva, M. Pinto, A. Pinto, M. Zalis, L. Carvalho and A. Krettli, Bioorg. Med. Chem. Lett., 2004, 14, 1145-1149; (d) C. Neves-Pinto, V. Malta, M. Pinto, R. Santos, S. Castro and A. Pinto, J. Med. Chem., 2002, 45, 740-743; (e) D. Cartwright, W. Chilton and D. Benson, Appl. Microbiol. Biotechnol., 1995, 43, 211-216; (f) J. Ligon, S. Dwight, P. Hammer, N. Torkewitz, D. Hofmann, H. Kempf and K. Pee, Pest Manage. Sci., 2000, 56, 688-695; (g) M. Muller and T. Sorrell, Prostaglandins, 1995, 50, 301311.

6 (a) H. Xue, X.-J. Tang, L.-Z. Wu, L.-P. Zhang and C.-H. Tung, J. Org. Chem., 2005, 70, 9727; (b) M. R. Gill, D. Cecchin, M. G. Walker, R. S. Mulla, G. Battaglia, C. Smythe and J. A. Thomas, Chem. Sci., 2013, 4, 4512; (c) S. M. Brombosz, A. J. Zucchero, R. L. Phillips, D. Vazquez, A. Wilson and U. H. F. Bunz, Org. Lett., 2007, 9, 4519; (d) S. Horiuchi, R. Kumai and Y. Tokura, J. Am. Chem. Soc., 2005, 127,
5010; (e) Q. Miao, Adv. Mater., 2014, 26, 5541; (f) U. H. F. Bunz, J. U. Engelhart, B. D. Lindner and M. Schaffroth, Angew. Chem., Int. Ed., 2013, 52, 3810; $(g)$ S. Horiuchi, F. Ishii, R. Kumai, Y. Okimoto, H. Tachibana, N. Nagaosa and Y. Tokura, Nat. Mater., 2005, 4, 163.

7 (a) E. E. Schweizer, N. O. Meeder, and G. P. Ellis in Chromenes, Chromanes, Chromones, Wiley-Interscience, New York, 1977; (b) G. Zeni and R. C. Larock, Chem. Rev., 2004, 104, 2285-2309; (c) K. C. Nicolaou, J. A. Pfefferkorn, A. J. Roecker, G. Q. Cao, S. Barluenga and H. J. Mitchell, J. Am. Chem. Soc., 2000, 122, 9939-9953; (d) K. C. Nicolaou, J. A. Pfefferkorn, H. J. Mitchell, A. J. Roecker, S. Barluenga, G. Q. Cao, R. L. Affleck and J. E. Lillig, J. Am. Chem. Soc., 2000, 122, 9954-9967; (e) K. C. Nicolaou, J. A. Pfefferkorn, S. Barluenga, H. J. Mitchell, A. J. Roecker and G. Q. Cao, J. Am. Chem. Soc., 2000, 122, 9968-9976.

8 A. Kumar, S. Sharma, R. A. Maurya and J. Sarkar, J. Comb. Chem., 2010, 12, 20-24.

9 (a) J. Hiramoto, A. Nasuhara, K. Michiloshi, T. Kato and K. Kikugawa, Mutat. Res., 1997, 395, 47-56; (b) G. Shanthi and P. T. Perumal, Tetrahedron Lett., 2007, 48, 6785-6789.

10 (a) T. A. Engler, K. O. LaTessa, R. Iyengar, W. Chai and K. Agrios, Bioorg. Med. Chem., 1996, 4, 1755-1769; (b) A. Elomri, S. Mitaku, S. Michel, A. L. Skaltsounis, F. Tillequin, M. Koch, A. Pierre, N. Guilbaud, S. Lèonce, L. Kraus, Y. Rolland and G. Atassi, J. Med. Chem., 1996, 39, 4762-4766; (c) M. Kidwai, S. Saxena, M. K. R. Khan and S. S. Thukral, Bioorg. Med. Chem. Lett., 2005, 15, 42954298; (d) C. Tahtaoui, A. Demailly, C. Guidemann, C. Joyeux and P. Schneider, J. Org. Chem., 2010, 75, 37813785; (e) K. Mukai, K. Okabe and H. Hosose, J. Org. Chem., 1989, 54, 557-560; (f) J. Jankun, S. H. Selman and R. Swiercz, Nature, 1997, 387, 561; (g) S. Paramonov, S. Delbaere, O. Fedorova, Y. Fedorov, V. Lokshin, A. Samat and G. J. Vermeersch, J. Photochem. Photobiol., A, 2010, 209, 111-120; (h) R. A. Evans and G. K. Such, Aust. J. Chem., 2005, 58, 825-830.

11 (a) L. F. Tietze and U. Beifuss, Angew. Chem., 1993, 105, 137; (b) L. F. Tietze, G. Brasche, and K. Gericke, Domino Reactions in Organic Synthesis, Wiley-VCH, Weinheim, 2006, p. 160; (c) L. F. Tietze, Chem. Rev., 1996, 96, 115; (d) L. F. Tietze, J. Heterocycl. Chem., 1990, 27, 47; (e) L. F. Tietze in Selectivity-A Goal for Synthetic Efficiency, ed W. Bartmann, and B. M. Trost, VerlagChemie, Weinheim, 1984, p. 299.

12 (a) M. J. Khoshkholgh, S. Balalaie, H. R. Bijanzadeh and J. H. Gross, ARKIVOC, 2009, ix, 114-121; (b) P. Biswas, J. Ghosh and C. Bandyopadhyay, Tetrahedron Lett., 2014, 55, 6882-6886.

13 (a) M. J. Khoshkholgh, M. Lofti, S. Balalaie and F. Rominger, Tetrahedron, 2009, 65, 4228-4234; (b) M. Mollazadeh, M. J. Khoshkholgh, S. Balalaie, F. Rominger and H. R. Bijanzadeh, J. Heterocycl. Chem., 2010, 47, 1200-1208; (c) N. J. Parmar, B. R. Pansuriya, B. M. Labana, T. R. Sutariya, R. Kant and V. K. Gupta, Eur. J. Org. Chem., 2012, 2012, 5953-5964; (d) T. R. Sutariya, B. M. Labana, B. D. Parmar, N. J. Parmar, R. Kantb and V. K. Gupta, RSC 
Adv., 2015, 5, 23519-23529; (e) K. C. Majumdar, T. Abu and N. R. Kumar, Tetrahedron, 2012, 68, 5693-5718.

14 (a) M. Bakthadoss, D. Kannan and R. Selvakumar, Chem. Commun., 2013, 49, 10947-10949; (b) M. Bakthadoss, A. Devaraj and D. Kannan, Eur. J. Org. Chem., 2013, 15051513; (c) M. Bakthadoss and G. Sivakumar, Tetrahedron Lett., 2014, 1765-1770; (d) M. Bakthadoss, D. Kannan, J. Srinivasan and V. Vinayagam, Org. Biomol. Chem., 2015, 13, 2870; (e) M. Bakthadoss and N. Sivakumar, Synlett, 2009, 1014; (f) M. Bakthadoss and G. Murugan, Synth. Commun., 2008, 38, 3406; (g) M. Bakthadoss and R. Selvakumar, J. Org. Chem., 2016, 81, 3391-3399; (h) M. Bakthadoss, N. Sivakumar and A. Devaraj, Synthesis, 2011, 4, 0611-0618.
15 (a) M. Bakthadoss, G. Sivakumar and D. Kannan, Org. Lett., 2009, 11, 4466; (b) M. Bakthadoss, D. Kannan, N. Sivakumar, P. Malathi and V. Manikandan, Org. Biomol. Chem., 2015, 13, 5597; (c) M. Bakthadoss and G. Sivakumar, Tetrahedron Lett., 2014, 55, 1765; (d) M. Bakthadoss, R. Selvakumar and J. Srinivasan, Tetrahedron Lett., 2014, 55, 5808; (e) M. Bakthadoss and D. Kannan, RSC Adv., 2014, 4, 11723.

16 (a) S. Paul and Y. R. Lee, Green Chem., 2016, 18, 1488-1494; (b) S. Vidyacharan, C. Adhikari, V. S. Krishna, R. S. Reshma, D. Sriram and D. S. Sharada, Bioorg. Med. Chem. Lett., 2017, 27(7), 1593-1597.

17 CCDC number for the crystal structure $\mathbf{4 l}$ and $\mathbf{8 b}$ are 1906333 and 1906667. 